\title{
Identity, language and social cohesion:Car plate number preference among Indonesian diaspora
}

\author{
A. B. Muslim \\ Department of English Education, Universitas Pendidikan Indonesia \\ Bandung, INDONESIA \\ abukhmuslim@upi.edu
}

\begin{abstract}
Social identification and cohesion are deemed important, particularly among group-oriented ethnic minorities like Indonesians overseas. This identification can be, in some other ways, expressed by car license numbers, to show their social belonging and affiliation. This qualitative study explores how a small number of Indonesians who live permanently in Australia and the United States, through their selection of unique car license numbers written in Bahasa Indonesia, show their social identity and cohesion as members of ethnic minority. Applying the language representation of Hall (1997), and social cohesion indicators (Reskeens et al., wy) to analyse various car license numbers and the underlying reasons of their owners' uses as evidenced from the results of semi-structured interviews, the study reveals various categories of social identification that this preference of certain car license numbers can disclose. Extending the results of previous studies, they include aspects of personal, ethnic, religious, professional, and childhood memory considered necessary for their social cohesion. The car plate numbers written in Bahasa Indonesia bond their sense of belonging to Indonesia. Meanwhile, these different social categories show who or what they are in relation to others in the community. Given that research on Indonesian diaspora is limited, this finding interestingly shows the participants' social cohesion and positive contribution to their country of origin while living away.
\end{abstract}

Keywords - social identification and cohesion, Indonesian diaspora, car license number

\section{INTRODUCTION}

Identifying with country of origin is a common phenomenon experienced by members of diaspora communities. Living overseas, they may miss home town, extended family, and other cultural memory. Due to this spatial obstacle, these diaspora families often make strong efforts to identify with their culture of origin while experiencing the lives of ethnic minority in their country of current settlement (Sam, 2000). To socially identify with their culture, parents of ethnic minority socialize their culture to their children in many ways possible such as using the ethnic language with children and exposing them to cultural commodities (costume, food, and musical instrument) (Moua \& Lamborn, 2010; Willoughby, 2005; Clyne, 2005).

Given the importance of social cohesion and identification among members of ethnic minority, diaspora communities, including those of Indonesians in Australia and the United States, have various ways of expressing their social identification with the culture of their country of origin. One of which is through the selection of car license number plates written in their own ethnic language, Bahasa Indonesia (Indonesian language), which can be used to show who they are in relation to the dominant culture and their social groups.
Not only can this use of ethnic language in selecting car license number show their affiliation with their ethnic culture of Indonesia but also express their social identification as minority groups to the dominant Australian and American cultures. Identifying their identification with both cultures is important since Indonesia and Australia are two neighbouring countries of difference. Geographically distant, a predominantly Muslim country with its eastern value orientation, Indonesia is also considered important by the United States, a Christian-majority country with Western culture.

This study explores the preference of several Indonesian diaspora in Australia and the United States in selecting unique car license plate number which are written in Bahasa Indonesia. Since the number of Indonesian diaspora is relatively small compared to other most populous countries in the world such as China and India, it is interesting to find out how these minor minority groups express their social identification as evidenced from their selection of automotive license number and how this has influence on their social identification and cohesion as ethnic minority group. Bruhn (2009) contends that due to its complexities, most attention of cohesion assessment is given to small rather than large group. Therefore, it is essential to explore the cohesion of Indonesian diaspora as ethnic minorities in the United States and Australia.

\section{LITERATURE REVIEW}

\section{A. Ethnic language and social cohesion}

Language is distinctive to human by which they express their feelings and social roles. It is an important social representation through which people show who they are in relation to their social environment (Hall, 1996; 2000) . For members of ethnic minority like Indonesian diaspora in the United States and Australia, the use of Bahasa Indonesia shows their social identification with Indonesia, their country or origin. To maintain this ethnic language, they may speak Bahasa Indonesia at home, ask their children to take Bahasa Indonesia class as practised by other ethnic minority groups (Moua \& Lamborn, 2010) and make unique car license numbers written in this ethnic language. Within their community, not only can this use serve as a social cohesion which unites them as Indonesians but also a means of showing who they are within the community.

The use of ethnic language for social cohesion is necessary. This cohesiveness is more important for members of a group who share emotional and behavioral characteristics between individual and group (Hogg, 1992). Ethnic language use also relates to some indicators of social cohesion which include 
marriage, church attendance, funerals, and population density (Reskeens, Botterman, \& Hoogle, wy). For more solemn rituals, marriage ceremony, attendance at worship places and funerals among members of ethnic minority are usually enacted in ethnic language. My personal observation, for instance, shows that marriage, worship, and funeral ceremonies among Indonesian diaspora in Melbourne, Australia, are always conducted in Bahasa Indonesia. It appears that the use of this ethnic language makes their social life more cohesive. They feel they are one extended family tied together by the use of Bahasa Indonesia. In this case, social cohesion enables people like members of ethnic minority, to manage collective action problems in a peaceful manner (Woolcock, 2011). This use of ethnic language increases their trust on each other, which is a key element in collective work (Reskeens, 2008). They may be of various local ethnicities of Indonesia such as Javanese, Padangese, Batakese, Sundanese and Balinese but feel Indonesian when they speak Bahasa Indonesia to each other.

Social cohesion is also negotiated through interests, relationships, and identities (Kelman, 2006). Shared ethnic language by members of ethnic minority bridges their interests, enhances relationship and shows their identity. In industrial society like Australia, sharing job opportunity is also 'central to the place of individuals in terms social status, relative wealth and power relations' (Norton \& de Haan, 2013; p. 32). This share indicates an important social cohesion among ethnic minority groups (Reskeens, Botterman, \& Hoogle, wy), which is a central societal goal, especially among diaspora communities (Berger-Schmitt, 2000) like the Indonesians in the United States and Australia who participate in this study.

\section{B. Automotive selection and social identification}

As saying goes, we are what we wear, drive, or ride. People conspicuously wear items such as well-known branded sunglasses and fashion clothing to project their self-images (O'class \& McEwen, 2004). The use of automotive vehicle such as car and motorcycle goes beyond pragmatic transporting purposes. As personal relationship with consumer goods has dominated the everyday life of people, mostly in western societies (Miles, 1998), people use vehicles to show their social identity and to enhance self-esteem (Sowden \& Grimmer, 2009). People do not only buy cars to be more mobile in fulfilling their necessities but also for prestige, showing their personal taste. To consciously enact their social identity, people will select and buy cars which have symbolic meanings relevant with their self-images. Sometimes, they make unusual choices from the majority so that they can effectively communicate their desired identities differently (Berger and Heath, 2007).

Various studies on the relation between automotive selection and social identification have been conducted. Within Western societies, a study of motoring behaviour of British people by Froud et al. (2005), reveals that cars, especially highstatus brands such as Mercedes, BMW or Jaguar, were used as symbols of identity and social status. In Indonesian context, in a study of car naming phenomenon among Indonesians, Prijambodo (2013) found that some cars are named after their owners. Following the first letter of the city or area in which the cars are registered, with creative use of rebus, some car names include B3AR, D3SI, H3NI, H4DI, C1CA, and so on. Most of them are the names of the owners showing to whom the cars belong. With this limitation, Indonesians have to combine letters and numbers to make names or other configuration they prefer to show their social identification.

Preference for unique car license number overseas is different from that in Indonesia. Unlike Indonesians, people overseas, including members of Indonesian diaspora communities in Australia and the United States, have more freedom in selecting unique car license number that they prefer. They are not restricted by the government regulation on regional initial letters as the case with Indonesians. Instead, they can freely choose words, numbers or phrases showing names, hobbies, and other special attributes that they wish to show their social identification. Considering this flexibility in selecting unique car license number overseas, it is interesting to explore how the Indonesian diaspora in Melbourne and Boston make use of their car license numbers as a means of their social identification and cohesion.

\section{THIS STUDY}

\section{A. Study method data sources}

This ethnography study relies on observation and informal talks as data sources. Guided observation focus on the preference of car license numbers that the participating Indonesian diaspora members in Melbourne, Australia and Boston, the United States have selected. Observations took place at some parking lots of Indonesian gatherings such as the Indonesian cultural events and community centres. The observation in the United States took one and half year, when the researcher was doing his Master study whereas that in Australia was for more than five years, when he was conducting his doctoral degree.

\section{B. Participants and instrument}

As many as six unique car license numbers were observed in both countries; one in Boston and another five in Melbourne. They belong to three Indonesian males and three females who have been permanent residents in the two cities. Having been informed about the nature of the study, all the car owners were consented to be involved in informal talks on their underlying reasons for selecting these unique car license plates. The semi-structured interviews were conducted at various places such as cultural events and community centers. Results of the semi-structured interviews was analysed on the basis of profession types and their meanings for social identification. Personal information of the participants remains anonymous. 


\section{FINDINGS AND ANALYSIS}

There are several types of unique car license numbers observed in this study. Due to short stay and small number of Indonesian diaspora in the city of Boston Massachusetts, the USA, only one sample of unique car license was observed in this city. Selected by a female Indonesian who is married to a US citizen, the car license number is UNYIL for her Mercedes sedan, observed in a parking area of a local university in Boston. UNYIL is the main characters of children's puppet film on Indonesian national television in late 1970s to early 1980s.

Meanwhile, since the observation in Australia took longer among a relatively larger number of Indonesian diaspora in this country, five samples of car license plates were identified. They are KIKI (male/female name) in New South Wales (NSW), and BETAWI (local ethnicity), HALAL (kosher), KONTOL (male genital) and PENARI (dancer) in Victoria (VIC) of Australia. These unique car license numbers are then categorized into several social groups based on their meanings as shown in Tables 1 and 2 .

TABLE I. CAR LICENSE NUMBERS, CITIES, AND OWNERS

\begin{tabular}{|c|c|c|c|c|c|}
\hline No. & $\begin{array}{l}\text { Car } \\
\text { numbers }\end{array}$ & license & \multicolumn{2}{|l|}{ Observed in } & Owners \\
\hline 1. & UNYIL & & \multicolumn{2}{|c|}{ Boston, MA, USA } & $\begin{array}{l}\text { Female, aged } \\
50 \mathrm{~s}\end{array}$ \\
\hline 2. & KIKI & & $\begin{array}{l}\text { Sydney, } \\
\text { Australia }\end{array}$ & NSW, & Male, age 40s \\
\hline 3. & HALAL & & $\begin{array}{l}\text { Melbourne, } \\
\text { Australia }\end{array}$ & VIC, & Male, age $50 \mathrm{~s}$ \\
\hline 4. & PENARI & & $\begin{array}{l}\text { Melbourne, } \\
\text { Australia }\end{array}$ & VIC, & $\begin{array}{l}\text { Female, ag } \\
40 s\end{array}$ \\
\hline 5. & KONTOL & & $\begin{array}{l}\text { Melbourne, } \\
\text { Australia }\end{array}$ & VIC, & Male, age 50s \\
\hline 6. & BETAWI & & $\begin{array}{l}\text { Melbourne, } \\
\text { Australia }\end{array}$ & VIC, & $\begin{array}{l}\text { Female, age } \\
40 s\end{array}$ \\
\hline
\end{tabular}

TABLE II. CAR LICENSE NUMBER, MEANING AND SOCIAL CATEGORY

\begin{tabular}{|c|c|c|}
\hline $\begin{array}{l}\text { Car license } \\
\text { number }\end{array}$ & Meaning & Social identification \\
\hline BETAWI & $\begin{array}{l}\text { A local Indonesian ethnic group } \\
\text { based in greater Jakarta area. } \\
\text { Betawi is derived from Batavia, a } \\
\text { name given to the city during the } \\
\text { Dutch occupation }\end{array}$ & Local ethnicity \\
\hline HALAL & $\begin{array}{l}\text { A religious/Islamic term } \\
\text { commonly used for food which } \\
\text { means kosher }\end{array}$ & Religion/piety \\
\hline KIKI & $\begin{array}{l}\text { Is a typical name of Indonesian, } \\
\text { can be male or female }\end{array}$ & Personal name \\
\hline KONTOL & $\begin{array}{l}\text { A male genital, mostly considered } \\
\text { rude to utter }\end{array}$ & Vulgarity, joke, \\
\hline PENARI & Dancer & Profession, career \\
\hline UNYIL & $\begin{array}{l}\text { A children movie displayed on } \\
\text { Indonesian national television } \\
(\text { TVRI) in late } 1980 \text { s and early } \\
\text { 1990s. }\end{array}$ & Childhood memory \\
\hline
\end{tabular}

Discussion of this study consists of two parts. The first section discusses how the selection of car license number shows the social identification of the participants within wider public Australia. The second part explores how this selection also depicts their social cohesion as members of ethnic minority group.

\section{A. Car license number and social identification}

Unlike Indonesians, people overseas including those Indonesian diaspora in the United and Australia have more freedom in preferring their unique car license numbers. They can choose any unique names without being restricted by initial letter for area as required for their Indonesian counterparts. They can select any personal names without any letter or number restrictions such as KIKI, JOHN, ARNOLD and MATHILDA. In Australia and the United States as well as other countries, area/state codes are usually written separately on the top or bottom part of the license number. It does not limit the creative expression of the vehicle owners in expressing their social identification through car license numbers.

The six license numbers identified in this study show the owners' different social identification with both the culture of Indonesia, their country of origin, and Australia or the United States, their current settlement countries. With various license numbers written in Bahasa Indonesia, each participant shows a different social identification in relation to the people of the dominant culture in which they reside permanently. The social identification includes personal name, local ethnicity, profession of a dancer, joke/vulgarity of male genital, religiosity of kosher food, and childhood memory as represented by a main character of an Indonesian children movie. In general, these unique car license numbers are distinctive identification of the participants which are expected to improve their social cohesion, esteem, and identification (Berger \& Heath, 2007; Miles, Sowden \& Grimmer, 2009; and Froud et al., 2005).

The first and most common category of automotive license number is personal name. A male participant who lives in Sydney, New South Wales (NSW) as shown by the license number, selects the word KIKI, his personal name. He believes that this selection will be able to show who he is, the owner of the car. He also admits that he is inspired by other Australians who put their names as their car license numbers. As studies have shown, labels such as John, Marry, Adam, and Stephanie are personal names commonly selected to show whom the car belong to. Studies also indicate that this use of unique car license for personal name is a common practice in Indonesian context. However, unlike their counterparts overseas, Indonesians have limitation in selecting their unique car license numbers so that they have to make use of rebus to show who they are (Prijambodo, 2013). This practice is not only applied to cars but also motor bikes.

The second social identification which this car license number shows is local ethnicity. One female participant who is originally from Jakarta area proudly selects BETAWI (from the word BATAVIA, Dutch name for the city now called Jakarta) as the license number for her hatchback car. At the time of 
study, she is married to a Lebanon-born Australian. Her previous marriage with an Australian has brought her to greater Melbourne in which she currently lives as a permanent resident. Living in Australia for more than fifteen years, as a Jakarta-born, she speaks Bahasa Indonesia with strong Jakarta accent among members of the Indonesian community and is very proud of her Betawi culture. This female participant said that she is a Betawi origin who does not want to lose the Betawi identity despite her permanent residency in Australia. For this participant, socializing cultural practices, including the name of local ethnicity of Betawi is one common practice that ethnic minority groups can do to maintain their social identification (Moua \& Lamborn, 2010; Willoughby, 2006; Clyne, 2005).

The third category is religiosity. One male participant selects HALAL, an Arabic word which means kosher, for his brand new sport car. Based on his selecting this religious term, the owner seems to be religious as he is frequently observed at the mosque of the Indonesian community, attending various religious activities such as sermons, prayers, and retreats. The main reason for this preference is because he is a chef who used to run a restaurant. This car license label serves as an assurance for Muslim community members in greater Melbourne area, his main targeted restaurant customers that the food he provides is in compliance with the Islamic law. When his HALAL restaurant was closed down, a friend of his who runs a similar business asked if he could buy the car license number. Feeling emotionally attached with the number, he rejected the offer. He said:

I prefer this license number because I used to run a halal restaurant. When I park my car in front of the restaurant, I want to show my potential customers, especially those of Muslims, that all the foods in my restaurant are halal. My customers should not doubt with my service. When I closed down the restaurant, my friend asked if he can buy the number for a big amount of money. I told him, no, I will not sell this number. It has an important history in my life (Male, 50s).

It seems that shared interest in religious activities which relates to relationship and identity, as Kelman (2006) suggests, has urged this male participant to select HALAL for his sport car. For him, sharing interest in religion makes him feel good as Muslim minority in Australia. He can also use this shared interest to build relationship with some potential customers of his restaurants who are mostly Muslim. Finally, this relationship of brother/sisterhood shape their Muslim identity who manage to only consume halal food.

Furthermore, HALAL also signifies the importance of religion in the life of most Indonesians. Regardless of their faith affiliations (Islam, Christianity, Hinduism and Budhism), Indonesians are religious. Living in a secular state of Indonesia, religiosity plays significantly in the life of most Indonesians, young and old (Nilan, 2008). This religiosity is maintained when they live overseas. My personal observation shows that all Indonesians in greater Melbourne area, of all faith affiliations, are religious. My personal engagement confirms that they are even more religious than their contemporaries in
Indonesia. Interview results show that, having been economically fulfilled, they feel grateful to God, their Creator and Sustainer. This gratitude is not only shown in their increased rituals but also more socially involved in welfare issues, especially for their countrymen in Indonesia.

Another category is vulgarity/joke. One male participant confidently selects the word KONTOL (male genital), for his minivan. This selection may be influenced by his personal life experience of being involved in drug life in Bali before his migration to Australia. This life style continued during his initial life in Melbourne but changed in the last decade. He now lives happily with his Indonesia-born wife and three children. These days, as the interview reveals, he sometimes feels embarrassed when parking his minivan in front of the Indonesian Muslim community centre. He needs to find a quiet place to park, not very close to the centre. At another time, however, he jokingly said that he likes parking his car beside the HALAL car that his friend has so that both can make a funny combination of KONTOL HALAL (kosher or edible male genital). He said;

This is actually a joke. You know, it is taboo to say this word in Indonesia. People who say this word will be considered impolite or bad. I want to show people that nothing wrong with this word. It is a part of our body. All males have this part. So, there is nothing wrong I think. But now I realize that this is not an appropriate word to select. So, every time I attend the gathering of Indonesian people, I often feel shy. I always find a quiet and distant parking spot (laughter) (Male, 50s).

Within this vulgarity/joke notion, however, this participant makes an unusual choice, a considered taboo action in Indonesian culture, to show his different desired identity (Berger and Heath, 2007). He wants to be seen different from other members of the community.

The fifth category is profession. One female participant selects the word PENARI (dancer) for her sedan. This license number was observed in the parking lot of a city town hall which held an Indonesian cultural event. Married to an Australian, the car owner is a professional dance who performs from one stage to another in various cultural events both within the Indonesian community and public Australia. She said that she wants to show all members of the Indonesian community in greater Melbourne area that her profession is a dancer. It is like building an image of a dancer in the minds of all community members as well as a distinguished identity among public Australia (Sowden \& Grimmer, 2009).

In addition to social identification, this selection may also serve as a personal promotion by which she will receive more invitations for dance performance. By the same token, performing Indonesian dances in cultural events enables the participant to promote Indonesian culture to wider Australian public. So, this profession enables the participant to show both her social identification as member of ethnic minority to wider Australian public and her social cohesion among the community group (O'class \& McEwen, 2004; Berger and Heath, 2007; . 
The last category of social identification is childhood memory or entertainment. One female participant in Boston selects the word UNYIL for her Mercedes sedan. The owner who is married to an American of Dutch origin feels culturally alienated as Indonesian. She longs for her childhood memory that she used to cherish with her extended family in Jakarta. One of her favourite children's television movies is SI UNYIL, a puppet movie on Indonesian children's life. She wants to be seen distinctive from other members of the Indonesian community and the public American in Boston.

Preference for UNYIL, who is the main character in a children's movie is interesting to explore. Having been living in the United States for more than 30 years among a small number of Indonesians, the owner of the car is one of senior members of the community. Long and permanent stay in the United States has grown her longing for childhood memory with her extended family in Jakarta, Indonesia. In addition, she also believes that UNYIL is a unique name that almost all Indonesians whose childhood was in late 1970 and early 1980 must be familiar with. Besides, she also seems to be proud of selecting UNYIL for her Mercedes sedan. Relevant to previous studies on the purchase of branded car as a symbol of social identity (Freud et al., 2000), this finding also reveals that the Boston participant seems to be proud of her Mercedes sedan as her social symbol which can also shows her social identification, an Indonesia-born who lives among the public US citizens.

\section{B. Bahasa Indonesia, representation and social cohesion}

This study also reveals how Bahasa Indonesia represents identification and enhances social cohesion. Not only does this selection of unique car license which are written in Bahasa Indonesia enable all participants to show their social identification as ethnic minority of Indonesia origin among public Australia and the United States, but also improve social cohesion among them. Despite their spatial distance, they believe that using Bahasa Indonesia for their car license numbers represent their feelings of being Indonesian while living away (Hall, 1996, 2000; Clyne, 2005; Willoughby, 2006). The use of Bahasa Indonesia at home and community centre during weekends and other cultural events enable them to show who they are, residents of the United States and Australia of Indonesia origin.

In an industrial country like Australia and the United States, employment serves as social identity, especially among blue collar workers like some Indonesians who participate in this study. People feel financially secured and socially esteemed when they are employed so that they strive to get paid jobs. This employment opportunity can be obtained and shared by people who similar language through social connection such as among members of ethnic minority. For them, job opportunity is 'central to the place of their social status, wealth, and power relations' (Norton \& de Haan, 2013; p. 32). During weekends, Indonesian diaspora in Melbourne and Boston get together in the community centre and other cultural events to share similar interests in culture, Indonesian language, including employment opportunities. This shared job opportunities indicates an important social cohesion among ethnic minority groups (Reskeens, Botterman, \& Hoogle, wy), which is a central societal goal, especially among diaspora communities (Berger-Schmitt, 2000) like the participating Indonesians in Australia and the United States in this study who share emotional and behavioral characteristics among group individuals (Hogg, 1992).

In addition, the selection of BETAWI also shows the importance of local ethnicity among Indonesians. As a multicultural country, Indonesia is an imagined identity (Andersen, 2006) which is interpellated by the authority (Farmer, 2003) through symbols such as the unifying national language of Bahasa Indonesia, Garuda as its coat of arms and Pancasila as the underlying values. As an imagined identity, Indonesian nationality is nurtured, one of which is through the use of Bahasa Indonesia as the unifying language, so that Indonesians, young and old, maintain and nurture it as their national identity. Most Indonesians have their own local ethnicities such as Javanese, Sundanese, Betawi, Batakese, Padangese, Balinese, Bugisi, and Madurese. These so called local ethnicities of Indonesia had, in fact, existed long before the independence of Indonesia in 1945. It is, therefore, no wonder that some Indonesians like this female participant may feel more Betawi, Sundanese, Javanese, and Balinese than Indonesian, especially among her Indonesian fellows. She may, however, feel more Indonesian when showing her social identification among public Australia.

Moreover, gender seems to influence the selection of the car license number. Females tend to be more personal, ethnic and romantic whereas males tend to be relaxing and joyous. Participating females in this study prefer local ethnicity (BETAWI), profession (PENARI/dancer) and childhood memory (UNYIL/children movie) whereas males prefer personal name (KIKI) and joke/vulgarity (KONTOL/male genital). Relevant to this finding, Broadbridge (2003) argues that males tend to prefer vulgar language than females.

Supporting some indicators of social cohesion which include marriage, church attendance, funerals, and population density (Reskeens, Botterman, \& Hoogle, wy), Bahasa Indonesia use strongly relates to these indicators. Members of Indonesian community, regardless of their faith affiliation use this ethnic language for marriage ceremony. Wedding party is a cultural event in which they express themselves in Bahasa Indonesia. Similarly, attendance of church, mosque, and pure (Hindu's shrine of Balinese Indonesians) and funeral is also conducted in this ethnic language. The larger the community such as that in Melbourne, the more intensive the use of Bahasa Indonesia. Meanwhile, the use of Bahasa Indonesia to indicate social cohesion is less intensive among Indonesian diaspora in Boston due to their small number.

Finally, identification with certain social groups also requires investment. The six participants have shown their willingness to spend extra money to obtain unique car license numbers written in Indonesian language to socially show who they are; members of ethnic minority of Indonesia origin. Norton (2000) suggests that this kind of effort, especially the use of ethnic language, is an investment that certain social groups, including members of the Indonesian diaspora community in the United States and Australia, have done to 
show their strong affiliation with the culture of Indonesia, their country of origin while living permanently in these two countries.

\section{CONCLUSIONS}

Having analysed the findings, this study come with several conclusions. First, the study has identified as many as six unique car license numbers selected by the participating Indonesian diaspora members in both Boston, the United States and Melbourne, Australia. The numbers include various professions such as personal name, local ethnicity, religiosity, vulgarity/joke, profession, and children's movie. This preference shows the use of car license numbers beyond their basic function for transportation purposes. In relation to the dominant Australian and American culture, these names which are written in Bahasa Indonesia show their cultural identification as members of ethnic minority. Among members of Indonesian diaspora community, these uses signify various social cohesion such as the importance of local ethnicity and shared job opportunities and other interests. In short, this preference for certain car license numbers represent who they are, as members of ethnic minority, in relation to public Australia as well as Indonesian diaspora community. This ethnic language is also used in various social cohesion indicators such as marriage, funeral, and religious programs.

As a final remark, given the case qualitative nature of this research, to provide stronger generalizability, further study should include members of Indonesian diaspora from other than these two countries (Australia and the United States) so that findings can be more generalized to Indonesian diaspora communities across the world.

\section{REFERENCES}

[1] Anderson, B. (2006). Imagined communities: Reflections on the origin and spread of nationalism. London: Verso.

[2] Berger, \& Heath, (2007). Where consumers diverge from others: Identity signaling and product domains. Journal of Consumer Research, 34, pp. 121-132.

[3] Berger-Schmitt, R. (2000). Social cohesion as an aspect of the quaity of societies: Concept and measurement. EU reporting working papers, Towards a European of social reporting and welfare measurement, Center for Survey Research and Methdology, 14, pp. 1-31.

[4] Boardbridge, J. (2003). An Investigation into Differences between Women's and Men's Speech. Module 5 Sociolinguistics, The University of Birmingham Centre for English Language Studies, pp. 1-26.

[5] Bruhn, J. G. (2009). The group effect. Springer Science. DOI 10.1007/978-1-4419-0364-8_2

[6] Farmer, B. (2003). The ideologies of everyday life. In Fran Martin (Ed.), Interpreting everyday culture (pp. 15-31). London: Edward Arnold Ltd.

[7] Froud, J., Johal, S., Leaver, A., Williams K. 2005. Different worlds of motoring: Choice, constraint and risk in household consumption. The Sociological Review, 53(1), 96-128.

[8] Hall, S. (1996). Who needs identity? In S. Hall \& P. D. Gay (Eds.), Questions of Cultural Identity ( $p p$. . London: Sage Publications.

[9] Hall, S. (2000). Who needs 'identity'? In Paul du Gay et al. (Eds). Identity: A reader. London: SAGE Publications.

[10] Hogg, M. A. (1992) The social psychology of group cohesiveness: From attraction to social identity. New York: New York University Press.

[11] Kelman, H. C. (2006). Interests, relationships, identities: Three central issues for individuals and groups in negotiating their social environment.
Annual Review of Psychology. 57, pp. 1-26. DOI: 10.1146/annurev.psych.57.102904.190156

[12] Miles, S. 1998. Consumerism as a Way of Life. London, Sage Publications.

[13] Moua, M. Y., \& Lamborn, S. D. (2010). Hmong American adolescents' perceptions of ethnic socialization. Journal of Adolesence Research, 25(3), 416-440.

[14] Nilan, P. (2008). Youth transitions to urban, middle-class marriage in Indonesia: Faith, family and finances. Journal of Youth Studies, 11(1), 65-82.

[15] Norton, B. (2000). Identity and Language Learning: Gender, Ethnicity and Educational Change. New York: Longman.

[16] Norton, A. \& de Haan, A. (2013). Social cohesion: Theoretical debates and practical applications with respect to jobs. Background paper for the World Development Report.

[17] O'Cass, A., McEwen, H. (2004). Exploring consumer status and conspicuous consumption. Journal of Consumer Behaviour, 4 (1), 2539.

[18] Prijambodo, V. L. (2013). Some cars in Indonesia have 'names': A linguistically creative use of rebus. Magister Scientiae, 33, pp. 38-48.

[19] Reskeens, T. (2008). Defining social cohesion in diverse societies: How generalized trust relates to social cohesion. Paper prepared for presentation on the Research Day of the Faculty of Social Sciences, Leuven, October 27, 2008.

[20] Reskeens, T., Botterman, S. \& Hoogle, M. (wy). Is social cohesion one latent concept? Investigating the dimensionality of social cohesion on the basis of the Kearns and Forrest (2000) typology. Center for Political Research, KULeuven.

[21] Sam, D. L. (2000). Psychological adaptation of adolescents with immigrant backgrounds. The Journal of Social Psychology, 140 (1), 525.

[22] Sowden, L. J. \& Grimmer, M. (2009). Symbolic Consumption and Consumer Identity: An Application of Social Identity Theory to Car Purchase Behaviour. ANZMAC, pp. 1-10.

[23] Woolcock, M. (2011). What distinctive contribution can social cohesion make to development theory, research, and policy? Paper presented at the OECD International Conference on Social Cohesion and Development, Paris. 